\title{
Republic of Mozambique: Poverty Reduction Strategy Paper- Joint Staff Advisory Note
}

The attached Joint Staff Advisory Note (JSAN) of the Poverty Reduction Strategy Paper for the Republic of Mozambique, prepared jointly by the staffs of the World Bank and the IMF, was distributed with the member country's Poverty Reduction Strategy Paper to the Executive Boards of the two institutions. The objective of the JSAN is to provide focused, frank, and constructive feedback to the country on progress in implementing its Poverty Reduction Strategy (PRS).

To assist the IMF in evaluating the publication policy, reader comments are invited and may be sent by e-mail to publicationpolicy@imf.org.

Copies of this report are available to the public from

International Monetary Fund • Publication Services

$70019^{\text {th }}$ Street, N.W. • Washington, D.C. 20431

Telephone: (202) 623-7430 • Telefax: (202) 623-7201

E-mail: publications@imf.org • Internet: http://www.imf.org

\section{International Monetary Fund} Washington, D.C. 



\title{
THE INTERNATIONAL MONETARY FUND AND \\ THE INTERNATIONAL DEVELOPMENT ASSOCIATION
}

\author{
REPUBLIC OF MOZAMBIQUE \\ Poverty Reduction Strategy Paper- \\ Joint Staff Advisory Note
}

Approved by David Nellor and Anthony Boote (IMF) and Gobind Nankani (IDA)

November 14, 2006

\section{INTRODUCTION}

1. In September 2006, the government formally approved its revised Action Plan for Reducing Absolute Poverty (Portuguese acronym PARPA; the Mozambican Poverty Reduction Strategy Paper). ${ }^{1}$ PARPA II was prepared by the government through broad-based consultations with major stakeholders and civil society in a more participatory approach than PARPA I, involving four national and ten provincial Poverty Observatories. It is built on the experience of PARPA I including the PRSP Annual Progress Report (BdPES, or Balanço do PES in Portuguese) presented to the Executive Boards of Directors of the International Development Association (IDA) and the International Monetary Fund (IMF) in June 2005, along with the Joint Staff Advisory Note (JSAN). ${ }^{2}$ PARPA II is the operational plan for the government's Five Year Program (2005-09) and for the first time includes a strategic matrix of key indicators, a joint effort by the government, donors and civil society. These indicators will be fully integrated into and monitored through the annual instruments of the Economic and Social Plan (PES in Portuguese) and BdPES. This planning and monitoring process, a good practice innovation, will be a key issue for implementation.

2. While maintaining its commitment to improve quality and access to social services, PARPA II recognizes that the "rapid, sustainable and broad-based growth" warrants more emphasis on the growth of the productive sectors with a more active role

\footnotetext{
${ }^{1}$ The revised PARPA 2005-09 is referred to as PARPA II for the remainder of the JSAN.

${ }^{2}$ The BdPES is also submitted to Parliament. Other background documents include the following government documents submitted to the national assembly: the budget execution report for 2005, the medium-term fiscal scenario (CFMP), and the state budget (OE). The government and the direct budget support donors annually review the past year's implementation in April, and agree on new commitments four weeks later. In September, a joint Mid-Year Review agrees on the performance indicators and targets for the following year. These reviews lead to an aide-mémoire that complement the BdPES and the PES. The most recent aide-mémoire (September 2006) was used as background for this JSAN.
} 
of the private sector. This strategy is reflected in a pillar approach based on the Five Year Government Program in contrast to the sectoral approach used in PARPA I. Staffs welcome this shift, which ensures consistency with the principal policy framework of the government and provides a more holistic view of development, enabling the building of synergies within each pillar and cross-cutting themes. In addition, a special role is provided to districts as the focus of development while small and medium enterprises (SMEs) form the engine of employment generation, facilitating a shift from the informal to the formal sector. There is also a clear recognition of the challenges related to HIV/AIDS with a credible strategy for accelerating the national response to the AIDS pandemic. Overall, the priority areas for public policy to sustain growth and poverty reduction, and improve service delivery are arranged under three pillars: (i) economic development; (ii) human capital; and (iii) governance.

3. This Joint Staff Advisory Note (JSAN) provides staffs' advice on key priorities for strengthening future annual progress reports and for ensuring effective implementation. It also highlights several critical areas for further analysis and elaboration of priority public actions. While Mozambique is on track to meet the Millennium Development Goals (MDGs) on poverty incidence, infant and maternal mortality, and access to safe drinking water, particularly in urban areas, other areas such as enrollment of upper primary school and beyond, particularly in rural areas, gender equality, and HIV/AIDS call for a more efficient service delivery and effective use of additional donor support.

\section{Poverty Situation}

4. Mozambique achieved impressive results under PARPA I, sustaining economic growth of 8 percent per year on average, and reducing the poverty headcount index from 69 percent in 1997 to 54 percent in 2003, supported by prudent macroeconomic policies, far-reaching structural reforms and substantial donor assistance. Growth has been "pro-poor" meaning that the rate of consumption growth of people below the poverty line was strongly positive due to agricultural expansion, greater nonfarm activities in rural areas, and a rise in employment income. The decline in headline inflation has also helped, as it tends to hit the most poor the hardest.

5. Staffs welcome that PARPA II objectives are consistent with the MDG targets. PARPA II aims at reducing the incidence of poverty further to 45 percent in 2009. Mozambique appears well placed to achieve the key MDGs of halving the poverty rate by 2015 as long as growth remains roughly above 5 percent. Staffs share PARPA II's view that sustained high, broad-based growth embedded in an environment of good governance is needed to reduce poverty incidence and improve service delivery in a sustained manner.

6. The quality of poverty diagnosis in PARPA II has improved considerably since PARPA I. PARPA II draws on the second household survey results and analysis (IAF 2002-03), which allow comparison of trends over a five-year period. The definition of poverty has been broadened, and the measurements of poverty are now more multidimensional, including quantitative (covering incidence, depth and severity of poverty as well as nutrition-based indicators) and qualitative information. These data used in the 
poverty diagnosis are considered to be relatively reliable and of good quality. Nevertheless, future poverty analyses could include aspects such as disempowerment, causes of poverty and vulnerability.

\section{Given the importance of smallholder agriculture for growth and poverty} reduction, staffs would welcome greater clarity as to how agricultural growth can be ensured through increased farm level productivity and greater access to markets. Smallholder agriculture is predominantly subsistence based and uses few productivity enhancing inputs. Furthermore, agricultural production and the livelihoods of certain groups remain vulnerable to bad weather as witnessed by the flooding in 2000 and drought in 2005 . The forthcoming rural development strategy should address the issues of raising agricultural productivity, market access, and reducing vulnerability to weather shocks.

\section{MACROECONOMIC AND FiSCAL FrAMEWORK}

8. The primary objective of PARPA II is to sustain broad-based growth and thus make further inroads into poverty reduction. PARPA II emphasizes the importance of consolidating macroeconomic stability through prudent monetary and fiscal policies in the context of a flexible exchange rate regime. Central to this strategy will be a gradual strengthening of the fiscal position underpinned by an average increase in revenue of 0.5 percent of GDP per annum. Economic growth is expected to remain pro-poor and at about 7 percent per annum, while inflation is controlled to single digits through monetary control. The staffs welcome the well-presented macroeconomic framework in PARPA II. Now that the post-conflict agricultural rebound has largely run its course and first generation reforms are completed, there is a need for a second wave of reforms to sustain rapid growth. PARPA II could have, thus, benefited from a more developed analysis of the sources of growth and means to sustain productivity growth.

9. The baseline fiscal scenario is focused toward achieving the PARPA II targets, but could be further elaborated and costed. The medium-term fiscal scenario (CFMP) clearly translates PARPA II into an expenditure framework. Its approval by the Council of Ministers for the first time in 2006 lends the CFMP credibility as a tool to guide the preparation of subsequent budgets and formed the basis for disseminating the 2007 budget ceilings. In this respect, staffs view that the CFMP could be included in future PARPA II progress reports (i.e., BdPES), resulting in greater clarity over medium-term fiscal outlays. However, staffs are concerned that the expenditure framework seems to be based on trends in sector expenditures compatible with the objectives and goals of PARPA II, and not necessarily on a full costing of policies and programs envisaged. There is a need to strengthen the technical and negotiation capacity for budget preparation at the line ministry level in order to improve the links between PARPA II targets and the budget, an important challenge for the medium term. There is also a need to continue improving the planning and budgeting process by buttressing the information on donor-financed expenditures in the CFMP including multiyear commitments both for program and sector level support with the help of the donors. The alternative fiscal scenarios, including additional MDRI-related spending, are illustrative and could be further developed in future annual progress reports 
reflecting the actual debt relief provided and priority expenditures budgeted. The staffs also see a need for a more detailed presentation of alternative scenarios, particularly the challenges related to managing a scaling-up of aid to meet the MDGs. In this regard, PARPA II could also be couched in a more long-term perspective, including a costing of MDGs to guide policy directions and garner additional donor assistance.

\section{The joint Bank-Fund Debt Sustainability Analysis of 2006 shows that debt} dynamics remain sustainable under the baseline and stress tests, albeit susceptible to a ratcheting up of nonconcessional external borrowing. Although Mozambique's risk of external debt distress is low and the new external borrowing envisaged in PARPA II is broadly consistent with staffs' medium-term macroeconomic framework and with debt sustainability, it would be useful to analyze the viability of alternative scenarios of external assistance through its impact on the debt sustainability outlook in future annual progress reports. In addition, staffs encourage the authorities to continue to seek an increase in the share of grants, improvements in the monitoring of consolidated public debt, and develop a comprehensive debt management strategy including evaluating the impact of potential commercial borrowing for large infrastructure projects.

11. Tax reforms have proceeded smoothly and enter a consolidation stage. The law creating the Central Revenue Authority (ATM) was approved by the Assembly in December 2005, supported by the approval of complementary legislation and regulation in June 2006, setting the stage for the appointment of the management body of the ATM. The next phase of the revenue administration reforms (2007-10), to be supported by a multidonor common fund, will focus on establishing the ATM as a sustainable, semi-autonomous institution, and improving operational performance to help achieve the medium-term revenue targets. The strong revenue performance recorded in 2005 and 2006 attest to the gains from administrative improvements, although some fine tuning of tax policy is required to broaden the tax base by eliminating unwarranted tax exemptions, implementing a simplified tax regime for SMEs, and adopting a comprehensive approach to the taxation of natural resource exploitation.

12. Large investments (so called megaprojects) in the mining and gas sectors have helped Mozambique gain considerable credibility with foreign investors, calling for refinements to the tax, transparency and regulatory regime. ${ }^{3}$ Total cumulative investment has been over US\$4 billion for 1997-2005, putting Mozambique "on the global FDI Map." The sector's contribution to the fiscal accounts has, however, been lagging due to generous tax exemptions. Now that investor confidence in Mozambique is stronger, staffs view that it is crucial that the government move forward very rapidly with the adoption of a mining fiscal regime in line with international best practice. In addition, it would be advisable to develop a more specific petroleum fiscal regime that would be embodied in the

\footnotetext{
${ }^{3}$ The mining sector is broadly interpreted to include Mozal, a megaproject, which produces aluminum billets from imported alumina using electricity generated by the Cahora Bassa hydroelectric plant.
} 
general tax law so as to avoid case by case negotiation of petroleum projects. ${ }^{4}$ PARPA II commits to maintaining a transparent environment to attract investment in petroleum exploration, and staffs encourage a timely implementation of the Extractive Industries Transparency Initiative (EITI) principles to improve transparency, revenue management and governance in the oil, gas and mining sectors to continue to attract productive investments.

\section{Public financial management (PFM) systems have shown major improvements through the rollout of the integrated financial management system (e-SISTAFE) according to the latest PEFA assessment. The Homoine version of e-SISTAFE was} satisfactorily rolled out to six ministries (agriculture, education, finance, health, planning, and public works) in July 2006. The six ministries to which the system was rolled-out are now satisfactorily executing their budgets for goods and services and capital expenditure. ${ }^{5}$ The authorities' medium-term e-SISTAFE Action Plan and Budget (APB) for 2006-09 includes the following main elements: the rollout of the budget execution module to all central and provincial entities, and its customization to district and municipalities needs; the introduction of Phase II of the budget formulation module; and the development of new modules and functionalities. Staffs view that the APB is well-structured and the proposed phasing of implementation is ambitious but feasible. The development of a payroll and pensions module should be a high priority for 2006-07, and was identified by the PEFA assessment to be a major fiduciary risk. The module is, however, dependent on the implementation of a fully integrated civil service database, with which the e-SISTAFE payroll module should be fully compatible. ${ }^{7}$

14. The government and its international partners have increased efforts to improve the monitoring and evaluation of expenditure projects and programs. It should be possible from next year to earmark programs through the budget formulation module of eSISTAFE, and to identify and track priority expenditures defined in PARPA II on a real time basis. Staffs agree that the authorities and donors should identify a revised set of priority programs to be monitored under PARPA II including MDRI-related expenditures. ${ }^{8}$ Good progress has been made in integrating donor-financed projects into the annual budget processes, although information on government accounting guidelines for externally-

\footnotetext{
${ }^{4}$ To date, the only major petroleum project operating in Mozambique is the Pande-Temane Gas Project, the contracts for which were signed in 2000. More recently, four international companies have been granted the right to start drilling for oil.

${ }^{5}$ Payments of salaries continue to be executed centrally by the accounting department of the Ministry of Finance.

${ }^{6}$ By end-June 2006, the government and the donors reached an agreement on the APB for 2006-09 and a new Memorandum of Understanding (MoU).

${ }^{7}$ Presently there are at least 12 different databases that maintain a register of public servants throughout the government. The government is developing a centralized register of public servants (CUF) with UTRAFE's collaboration.

${ }^{8}$ In doing so, it would be preferable to monitor both economic and functional classifications of spending, covering current and capital expenditures by geographical regions.
} 
financed projects that are brought "on budget" require clarification. Challenges also remain in executing donor-financed projects through the treasury single account (CUT) and eSISTAFE, and the use of national procedures such as procurement, accounting, reporting and audit which needs to be further strengthened with close collaboration with donors.

\section{IMPROVING THE INVESTMENT CLIMATE}

\section{A good investment climate is essential for the development of private sector,} thereby fostering broad-based growth and employment creation. While PARPA II addresses the area of investment climate, staffs are concerned that it does not provide a clear vision and a strategy for doing so. In light of the cross-cutting and varied nature of most investment climate issues, staffs welcome the government's commitment to adopting a multiministerial sequenced long-term strategy to improve the investment climate, so as to create a consensus on the way forward and to increase the likelihood of having successful reforms.

16. Finance and trade can accelerate the engines of growth and help cushion against exogenous shocks. The PARPA II objectives regarding the financial sector are consistent with the recommendations of the FSAP to ensure financial stability by strengthening supervision and modernizing accounting standards, and to enhance the scope of financial intermediation by supporting the sound expansion of the nonbank financial sector (insurance, microfinance, savings cooperatives for smallholders, and pensions). In this regard, staffs would welcome the specific measures to regulate private pensions and reform the National Social Security Fund (INSS) based on an actuarial study to ensure sustainability. The strategic matrix is, however, sparse on actions to reduce the cost and increase access to finance by improving the lending environment, such as legal and judicial reform, use of landuse titles as collateral, and availability of credit information, as well as deepening of domestic debt markets. Trade reform and regional integration should also be given greater priority to promote export diversification as spelled out in the Diagnostic Trade Integration Study (DTIS).

17. Accelerated justice sector reform will remain a key to improving the investment climate. The weaknesses in the justice sector and a lack of transparency will continue to impede the development of a viable private sector in particular due to the slow contract enforcement process, which makes debt collection costly, slow and unlikely. There is a clear need to develop a sector strategy and establish measurable performance indicators to monitor progress in the sector in delivering its services. The performance against these indicators could be disseminated to the general public in order to help foster a better image in the judiciary system.

18. The ongoing revision of the Labor law is a step in the right direction, and staffs urge the government's continued efforts to increase labor market flexibility. Whilst the new draft Labor law addresses some important labor market rigidities, weaknesses remain in the areas such as working hours (overtime, night and weekend work), paid leave, and retrenchment costs. As such, staffs view the need for continued revision of the law to address the remaining shortcomings as the implementation of the new draft law takes place. 


\section{BUILDING Human CAPITAL}

19. Substantial progress was made in the social sectors under PARPA I, partly due to the increased resources made available as a result of the Heavily Indebted Poor County (HIPC) initiative. Noteworthy achievements include the doubled primary enrollment rate, a significant fall in maternal and infant mortalities, and a free provision of ARV treatments for HIV infection. However, the lack of progress in rural water supply and sanitation remain a concern.

20. Overall, the approach laid out for the education, health and water sectors in PARPA II is considered of good quality and consistent with the sectoral priorities and with achieving the MDG targets. Following the completion of the education sector strategic plan (Strategic Education and Culture Plan, or PEEC), the health and water resources management strategies need to be finalized to realize the envisaged targets, including provision of quality sustainable water and sanitation services in smaller cities and towns.

21. PARPA II is found to be a credible strategy for accelerating the national response to the AIDS pandemic within the framework of the National Strategic Plan to Fight HIV/AIDS (PEN II 2005-09). In particular, there is a good analysis of the impact of HIV/AIDS on women. However, the mainstreaming of gender issues in the health section is weak, as is the question of vulnerability of younger women with regard to HIV and the practice of parallel sexual relationships in the spread of HIV/AIDS.

\section{DeliVERING PUBLIC SERVICES}

22. A more efficient and effective delivery of public service will be essential to meeting most of the PARPA II targets. The first phase of the public sector reform program (2001-05) made some progress, but in general has been lagging behind reforms in the PFM area. However, staffs are encouraged by the recent establishment of the National Civil Service Authority (ANFP), which reports directly to the President, to give the reform effort stronger leadership and focus, and the preparation of the phase II of the public sector reform (2006-11) with more restricted priorities and more directed to the impact on citizens' lives. Clear action plans aimed at approving and implementing the salary reform (installation of a civil service database based on a comprehensive census) are reflected in the strategic matrix. ${ }^{9}$

23. Staffs welcome the government's incremental approach to extending administrative and fiscal powers to provinces and districts. This allows for the consolidation of fiscal control, and improved accountability, during the critical period in which SISTAFE is being rolled out to the local level. ${ }^{10}$ In addition, staffs view the operation

\footnotetext{
${ }^{9}$ The ministry of state administration deals essentially with local and municipal government, while the ANFP is expected to take strategic control of the central and provincial state apparatus.

${ }^{10}$ The rollout of e-SISFTAFE to districts and municipalities included in the SISTAFE action plan for 2006-09 should be gradual, based on their administrative capacity, and tailored to their needs.
} 
of the new procurement system up to the district level as a priority in line with the PARPA II matrix. Staffs also welcome the government's proposed review of inter-governmental fiscal relations as local government entities have limited autonomy in decision-making and are almost entirely dependent on government transfers for financing their expenditure, ${ }^{11}$ which should shape future reforms in this area. ${ }^{12}$ Such a review might also cover the fiscal arrangements for transferring funds to municipalities, which need to be reassessed.

24. The objective of the reform program is also to intensify the work on governance and capacity building while moving into new areas such as legal and judicial reform, the restructuring of government ministries, and the development of a human resource management system. With regard to the restructuring of ministries, staffs would recommend a more focused approach. Governance measures are also being targeted through a range of measures in addition to those included in the PFM work program. ${ }^{13}$ However, staffs are concerned that there have been few concrete actions to actually implement the recently approved Anti-Corruption Strategy. Continued emphasis on separation of powers and transparency is needed to combat the widespread perception of government interference.

\section{ImPlementation Risks, Monitoring ANd Evaluation OF PARPA II}

\section{To successfully implement PARPA II, the issue of developing institutional and} technical capacity needs urgent attention alongside good governance. The decentralization process, for example, poses considerable fiscal risks and challenges for capacity building at the local level, thus the authorities should take a more strategic approach to this issue with appropriate checks and balances. The weaknesses in the justice sector are causing an increasing impediment not only in dealing with criminal cases and corruption, but in relation to labor issues and the development of the private sector. This area thus constitutes a risk for PARPA II implementation.

\section{Staffs welcome the government's approach to monitor PARPA II} implementation through the annual instruments of the PES and BdPES, in which the key indicators of the PARPA II strategic matrix are integrated, and its proposal to produce an Annual Impact Report (RAI) at the end of the PARPA II period. However, broad participation to strengthen domestic accountability in PARPA II implementation and

\footnotetext{
${ }^{11}$ Recently, districts have each been given additional budgets of MTN 7 million (plus in a selected number of cases, 49 out of 129 districts, MTN 3 million from a World Bank project, thus more than doubling the budget of these districts) over which they have authority to determine priorities, but this amount is small in relation to overall public expenditure.

${ }^{12}$ Such a review might cover inter alia: the appropriate allocation of responsibility for various categories or functions of government between central, provincial and district government ("expenditure assignments"); the similar allocation of responsibility for taxes and other government revenues ("revenue assignments"); and the arrangements for making transfers between central government, provinces and districts in order to equalize for varying levels of population, poverty, revenue-raising capacity, etc. in the provinces and districts.

${ }^{13}$ For example, steps are being taken to strengthen the role of the government's internal audit authority, the Inspection General of Finance (IGF) and perform greater financial audits, which are important.
} 
monitoring needs consolidating through the provincial and district institutional mechanisms (Provincial Poverty Observatories and the Community Participation and Consultation Institutions), many of which are still in their infancy. The government will also have to ensure that the separation of the planning and finance functions into two separate ministries will not create problems for the implementation and monitoring of PARPA II and the relationship between the CFMP and the OE.

27. Effective monitoring of progress will depend on the alignment of the data collected for the PARPA II strategic matrix and the degree of integration of these indictors into the PES and BdPES. To ensure the alignment of the data collected by the National Statistic Institute (INE) and data required for effective monitoring of PARPA II implementation, there is a clear need to develop a data collection plan, which is harmonized with the statistic plan of the INE. Furthermore, staffs view the need to develop systems for a timely delivery and improved dissemination of key results to the public, the ultimate beneficiaries, for effective feedback.

\section{CONCLUSIONS AND ISSUES FOR DISCUSSION}

28. The strategy to consolidate macroeconomic stability and accelerate the second wave of reforms in PARPA II should facilitate sustained broad-based growth and poverty reduction. This will require a two-pronged strategy of persevering with the stabilization effort, and buttressing the investment climate by reducing the cost of doing business and strengthening good governance. To help achieve the MDGs, the government should ensure that additional external financing including MDRI resources are allocated to defined priorities and guarantee that there is value for money in public spending. Mediumterm PFM reforms and the public sector reform program more generally are key areas that require monitoring in this regard. Priority areas for further strengthening PARPA II include developing and implementing a strategy for improving the investment climate and modernizing the judicial system as well as the steadfast execution of the anti-corruption strategy. Staffs also welcome the willingness to strengthen the transparency of natural resources and megaprojects by adhering to the principles of the EITI. However, adoption of the mining fiscal regime in line with international best practice requires urgent action. Without these second-generation reforms, growth could suffer.

29. Do the Executive Directors concur with the areas identified by staffs: (i) as key for sustaining broad-based growth and achieving the MDGs; (ii) as priorities for strengthening the PARPA II, particularly reducing the cost of doing business and management of natural resources; (iii) as implementation risks related to capacity constraints and governance; and (iv) as key for successful PARPA II implementation, particularly PFM and public sector reforms. 